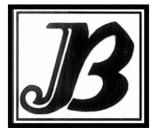

J. bio-sci. 22: 21-29, 2014

ISSN 1023-8654

http://www.banglajol.info/index.php/JBS/index

\title{
ANTIMICROBIAL ACTIVITIES OF SOME STREPTOMYCES ISOLATED FROM GARDEN SOIL SAMPLES AND FISH POND WATER IN FUTA
}

\author{
Ekundayo F O*, Oyeniran K A, Adedokun A D \\ Department of Microbiology, Faculty of Science, Federal University of Technology, Akure (FUTA), Nigeria
}

\begin{abstract}
Context: Streptomyces are potential sources for secondary metabolites possessing a variety of biological activities with antimicrobial activity, which is used for human and animal treatment. It is estimated these bacteria synthesize more than 7,000 metabolites. About $80 \%$ of these are made by members of the genus Streptomyces. Streptomyces spp. is known as producers of several bioactive metabolites which has antibiotic, antiparasitic, antitumor, insecticide, herbicide, etc.

Objectives: Determine the antimicrobial activities of Streptomyces isolates and compare the efficacy of the antimicrobial activities of Streptomycetes with selected commercial antimicrobial agents.

Materials and methods: Collection of samples and test organisms; physicochemical screening; antimicrobial assay (co-culture method); antibiotics sensitivity test (disc-diffusion assay).

Result: Streptomyces griseoflavus, Streptomyces parvus and Streptomyces albidus were isolated from dry soil while Streptomyces vinaceus and Streptomyces globiosporus from moist-fresh soil and fish pond water used for cultivation of cat fish Clarias garienpinus respectively. Out of these five (5) isolates isolated, 3 isolates (60\%) exhibited antibacterial activity against the following pathogenic, nosocomial organisms: Escherichia coli, Klebsiella pneumoniae, Salmonella typhi, Pseudomonas aeruginosa, Staphylococcus aureus, Candida spp, Aspergillus fumigatus, Aspergillus flavus, Aspergillus saprophyticus, and Trichoderma spp respectively. S. griseoflavus demonstrated antibacterial activity against $K$. pneumoniae, Trichoderma spp and Candida spp. S. albidus against S. typhi and A. fumigatus while $S$. parvus was inhibitory to $S$. aureus and $A$. fumigatus. The active isolates inhibited bacteria growth (0 to $39.33 \mathrm{~mm}$ ). Commercial antimicrobials used also demonstrated inhibitory effects against the test pathogens.

Conclusion: The garden soil of FUTA farm contains Streptomyces spp. with antibacterial and antifungal activities.
\end{abstract}

Key words: Antibacterial, Antifungal, Nosocomial, Novel drugs.

\section{Introduction}

Streptomycetes are soil-resident mycelial bacteria that make numerous secreted proteins and many vital secondary metabolites with useful antibiotics inclusive. Chitin serves as the foremost nutrient source for majority of Streptomycetes; apart from the fact that they have also developed extracellular system that facilitates its timely utilization (Chater et al. 2009). Streptomycetes are armed with discrete features such as DNA with a high Guanosine + Cytosine content (Anderson and Wellington 2001).

The Streptomyces genus is designated in nature by the vast amount of species coupled with the conspicuous diversities among their order. They demonstrate substantive variations in their morphology, physiology and biochemical actions, producing most known enzymes (Suneetha and Zaved 2011). More than 500 Streptomyces spp. and subspecies have been described, the most vast number of any bacterial genus (Lee et al. 2005). Several methods have been employed to identify Streptomyces species include culturing methods using the selective technique, construction of genetic marker systems, a combination of

\footnotetext{
* Corresponding author E-mail: foekundayo@futa.edu.ng
} 
chemical markers and the presence of LL-diaminopimelic acid plus the absence of characteristic sugars in the cell wall (Sujatha et al. 2005). Streptomyces species have been the most copious and easily recovered actinomycetes group in soil. Streptomyces produce secondary metabolites with varied bioactivities that are not limited to antibacterial, antifungal, antiviral, antitumoral, and enzyme inhibitory compounds (Àarthi et al. 2009). It is estimated these resourceful bacteria synthesize more than 7,000 metabolites (Berdy 2005). More than 9,000 biologically active molecules have been isolated from Streptomyces of which over 60 are applicable in medicine, agriculture and research (Demain 2009).

Among the actinomycetes, the genus Streptomyces has continued to provide a larger number and wider variety of new antibiotics than any other genus, signifying that a considerable number of Streptomyces spp. with novel antibiotic production capabilities exist in nature. These bacteria produce about $75 \%$ of commercially and medically useful antibiotics (Berdy 2005). Streptomyces are also well recognized as biological control agents that hamper several soil and airborne plant pathogenic fungi (Og et al. 2008; Silva et al. 2008). Streptomyces spp. are important source of abundant secondary metabolites, enzymes and antibiotics (Ahmed et al. 2008) chiefly due to their much shorter generation time, and the ease of genetic and environmental stage management. Although thousands of antibiotics have been isolated from Streptomyces, these represent only a small fraction of their catalogue of bioactive compounds potentials (Watve et al. 2001). The emergence of antifungal resistant fungi is a problem of growing significance in dermatological and surgical wound infections (Panacek et al. 2006). In general, the most important resistance problems in the management of wounds have been observed.

Therefore, isolation of new Streptomyces from natural resources, niches with promising potentials and characterization of their secondary metabolites is a valuable venture. The isolation of novel Streptomyces spp. is in great urgent need in this era of constantly evolving antimicrobial resistance, as they are very potent producers of innovative secondary metabolites (Mellouli et al. 2003).

\section{Materials and Methods}

\section{Collection of samples and test bacteria}

Fish pond water and soil samples were collected separately from agric farm and the fish pond within the Federal University of Technology Akure (FUTA) respectively. The following clinical pathogenic bacteria strains were also collected from the Ondo State Specialist Hospital, Akure and University college hospital Ibadan: Escherichia coli, Klebsiella pneumoniae, Salmonella typhi, Pseudomonas aeruginosa and Staphylococcus aureus, Candida spp. Aspergillus fumigatus, Aspergillus flavus, Aspergillus saprophyticus, and Trichoderma spp. Their identities were confirmed and maintained at $4^{\circ} \mathrm{C}$ till further analysis. All the laboratory reagents and chemicals used were of analytical standards.

\section{Analysis}

The parameters for water analysis are: $\mathrm{pH}$, turbidity, Nitrate, phosphate, Sulphate, Calcium, Magnesium, heavy metal, total dissolved solids, electrical conductivity, biochemical oxygen demand (BOD) and chemical oxygen demand (COD) while that of soil sample include: particle size analysis, $\mathrm{pH}$, organic carbon, calcium, magnesium, potassium, sodium, phosphorus and nitrogen according to Association of Analytical Chemists (AOAC 2007) standards.

\section{Isolation and identification of Streptomycetes}

With a sterile 1-ml pipette, $0.5 \mathrm{ml}$ from the dilutions $10^{-7}, 10^{-5}$ and $10^{-2}$ obtained from the fish pond water, moist fresh soil and dry soil samples respectively were aseptically transferred to already labeled Macbeth scales starch mineral agar (Soluble starch:10g, $\mathrm{CaCO}_{3}: 3 \mathrm{~g}, \mathrm{~K}_{2} \mathrm{HPO}_{4}: 1 \mathrm{~g},\left(\mathrm{NH}_{4}\right)_{2} \mathrm{SO}_{4}: 2 \mathrm{~g}, \mathrm{MgSO}_{4} \cdot 7 \mathrm{H}_{2} \mathrm{O}: 1 \mathrm{~g}$, $\mathrm{NaCl}: 1 \mathrm{~g}$, Agar:25g, pH:7.0) plates supplemented with $1 \mathrm{ml}$ of liquid Nystatin to inhibit fungi and spread with 
the aid of sterile glass spreader. The plates were incubated upside down in the dark at $28^{\circ} \mathrm{C}$ for seven days. Observed colonies on the plates were further examined microscopically to confirm their conformities to typical filamentous Streptomycetes. Isolates of different colonies were sub- cultured repeatedly by streaking on both pridham's medium (Glucose:10g, Starch:2g, $\left(\mathrm{NH}_{4}\right)_{2} \mathrm{SO}_{4}: 2 \mathrm{~g}, \mathrm{CaCO}_{3}: 1 \mathrm{~g}, \mathrm{~K}_{2} \mathrm{HPO}_{4}: 1 \mathrm{~g}, \mathrm{MgSO}: 1 \mathrm{~g}$, $\mathrm{NaCl}: 1 \mathrm{~g}$, Agar:12g, pH:7.0) and Streptomycetes growth medium (Glucose:10g, Peptone:1g, KNO$: 1 \mathrm{~g}$, $\mathrm{K}_{2} \mathrm{HPO}_{4}: 0.1 \mathrm{~g}$, Agar:15g, $\mathrm{pH}: 7.0$ ) until pure cultures were obtained. These different pure cultures were then introduced into a starch mineral agar slant and incubated for seven days at $28^{\circ} \mathrm{C}$ in order to ensure proper growth. The bottles were kept as stock cultures maintained at $4^{\circ} \mathrm{C}$ after identified after applicable morphological and biochemical tests with robust reference to Bergey's manual of determinative bacteriology and colour codes for exact description of colours of Streptomycetes according International Streptomycetes Project - ISP methods (Shirling \& Gottlieb 1966).

\section{Antimicrobial bioassay by co-culture method Agar plug method}

The selected pathogenic microorganisms; E. coli, K. pneumoniae, S. typhi, P. aeruginosa, S. aureus Candida spp. A. fumigatus, A. flavus, A. saprophyticus, and Trichoderma spp were grown in Mueller Hinton broth for twenty four hours (Bacteria) and Potato dextrose agar for forty eight hours (Fungi). Inoculum containing approximately $1.5 \times 10^{8}$ number of cells were swabbed on the surface of separately well labeled Mueller Hinton agar plates for bacteria and $0.5 \mathrm{ml}$ of the standardized inoculum was seeded into the Potato dextrose agar for fungi by pour plate method. Isolated Streptomyces strains were previously grown on Streptomycetes growth medium for Seven days to allow antibiotic production in the agar. Colonies of Streptomyces were cut using a sterile cork borer (8mm in diameter) and placed on the plate already inoculated with test organism and incubated at $37^{\circ} \mathrm{C}$ for 24 hours for bacterial and $28^{\circ} \mathrm{C}$ for $48 \mathrm{hrs}$ for fungi, growth inhibition of the indicator organisms was observed by measuring and recording the diameters of circular zones of inhibition in millimeters (Fokkema 1973).

\section{Perpendicular streaking method}

A single streak of Streptomyces from pure culture was made down the edge of Streptomycetes assay media. The plates were then incubated for about seven days in order to allow antibiotics to be produced; after which a single streak of each test organism was put perpendicularly to the Streptomyces without touching it for bacterial while agar plugs of test fungi already in confluence growth were aseptically placed next to the Streptomyces streak without touching it. After incubation, inhibition zones were measured and compared with the control experiment. Standard antimicrobial agents were also used against the test organisms as positive control and comparative purposes (Fokkema 1973).

Table 1. Physicochemical characteristics of fish pond water sample used.

\begin{tabular}{llll}
\hline Physicochemical characteristics & & & \\
\hline & & & \\
pH & 6.800 & Calcium $(\mathrm{mg} / \mathrm{l})$ & 17.000 \\
Conductivity (Ms/cm) & 0.006 & Chloride $(\mathrm{mg} / \mathrm{l})$ & 28.000 \\
Turbidity (NTU) & 140.000 & Sulphate $(\mathrm{mg} / \mathrm{l})$ & 0.600 \\
TDS $(\mathrm{mg} / \mathrm{l})$ & 790.000 & Phosphate $(\mathrm{mg} / \mathrm{l})$ & 1.400 \\
COD $(\mathrm{mg} / \mathrm{l})$ & 159.000 & Nitrate $(\mathrm{mg} / \mathrm{l})$ & 2.240 \\
BOD $(\mathrm{mg} / \mathrm{l0}$ & 1.690 & Copper $(\mathrm{mg} / \mathrm{kg})$ & 0.050 \\
Magnesium $(\mathrm{mg} / \mathrm{l})$ & 1.800 & Zinc $(\mathrm{mg} / \mathrm{kg})$ & 0.080 \\
\hline
\end{tabular}




\section{Results}

\section{Physicochemical Analysis of samples}

The physicochemical traits of the fish pond water suggest the water was very low in some vital nutrients on which the growth of Streptomycetes is predicated. For instance, Calcium was $17.00 \mathrm{mg} / \mathrm{l}$ and Nitrate $2.240 \mathrm{mg} / \mathrm{l}$ (Table 1). The soil was fairly higher in Calcium and Magnesium contents when compared with that of fish pond water above (Table 2).

Table 2. Physicochemical characteristics of soil sample used.

\begin{tabular}{|l|l|}
\hline \multicolumn{2}{|c|}{ Physicochemical characteristics } \\
\hline$\%$ Silt & 25.70 \\
\hline$\%$ Clay & 17.60 \\
\hline $\mathrm{pH}: 1: 2 \mathrm{H}_{2} \mathrm{O}\left(29^{\circ} \mathrm{C}\right)$ & 5.80 \\
\hline Organic carbon $(\mathrm{Mg} / \mathrm{l})$ & $2.3 \times 10^{-5}$ \\
\hline Calcium $(\mathrm{Mg} / \mathrm{l})$ & 200400.00 \\
\hline Magnesium $(\mathrm{Mg} / \mathrm{l})$ & 24305.00 \\
\hline Potassium $(\mathrm{Mg} / \mathrm{l})$ & 37925.06 \\
\hline Sodium $(\mathrm{Mg} / \mathrm{l})$ & 8736.20 \\
\hline Phosphorus (Mg/l) & 205977.10 \\
\hline Nitrogen (Mg/l) & $1.9 \times 10^{-5}$ \\
\hline
\end{tabular}

Table 3. Colonial, cellular, physiological and biochemical characteristics of Streptomycetes isolates.

\begin{tabular}{|c|c|c|c|c|c|}
\hline Macroscopic characteristics & Isolate B & Isolate J & solate $\mathrm{E}$ & te $\mathrm{H}$ & Isolate F \\
\hline Colony shape & Undulate & Circular & Irregular & Circular & Circular \\
\hline Colony colour & White & Brown & Grey & Orange & Yellow \\
\hline Colony edge & Rough & Smooth & Undulate & Rough & Round \\
\hline Elevation & Papillary & Umbonate & Raised & Convex & Convex \\
\hline \multicolumn{6}{|l|}{ Microscopic characteristics } \\
\hline Gram reaction & + & + & + & + & + \\
\hline Shape/structure & Filamentous & Filamentous & Filamentous & Filamentous & Filamentous \\
\hline Spore staining & + & + & + & + & + \\
\hline \multicolumn{6}{|l|}{ Biochemical investigations } \\
\hline Catalase & + & - & - & - & - \\
\hline Starch hydrolysis & + & + & + & + & + \\
\hline \multicolumn{6}{|l|}{ Carbon sources utilization } \\
\hline Glucose & + & + & + & + & - \\
\hline Lactose & + & + & + & + & - \\
\hline Fructose & + & + & + & + & - \\
\hline Mannitol & + & + & + & - & + \\
\hline Sucrose & - & - & - & + & - \\
\hline \multirow[t]{2}{*}{ Plausible Actinomycete } & Streptomyces & Streptomyces & S Streptomyces & Streptomyces & Streptomyces \\
\hline & griseoflavus & parvus & albidus & vinaceus & globiosporus \\
\hline
\end{tabular}




\section{Streptomycetes isolates}

Streptomycetes colony forming units obtained are $5.0 \times 10^{7}, 5.0 \times 10^{7}$ and $1.0 \times 10^{8}$ for fish pond water, moist-fresh soil and dry soil samples respectively. It was observed that dry soil has the highest colony forming units. Five different Streptomycetes species were isolated from fish pond water, moist-fresh soil and dry soil samples respectively. Physical and biochemical details of these isolates can be seen in table 3 . These isolates were grouped according to their sources: Streptomyces globiosporus was isolated from the fish pond water. Streptomyces vinaceus was isolated from moist-fresh soil. Streptomyces griseoflavus, Streptomyces parvus and Streptomyces albidus were isolated from soil sample that was air-died for two weeks.

\section{Screening of isolates for antimicrobial activity}

As depicted in figure 1, Streptomyces griseoflavus showed distinct antibacterial activities against Klebsiella pneumoniae and Salmonella typhi with zone of inhibitions ranging from 32.00 to $39.33 \mathrm{~mm}$ respectively while
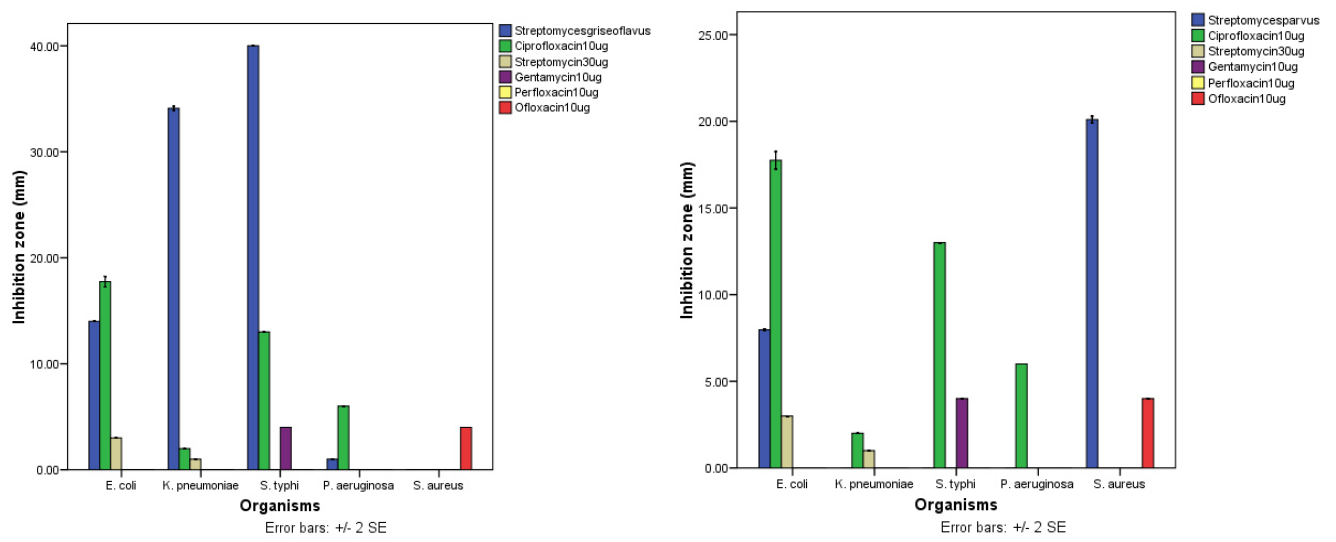

Fig. 1. Comparative antibacterial activities of Streptomyces griseoflavus and commercial antibiotics on selected pathogenic organisms. Fig. 2. Comparative antibacterial activities of Streptomyces parvus and commercial antibiotics on selected pathogenic organisms.
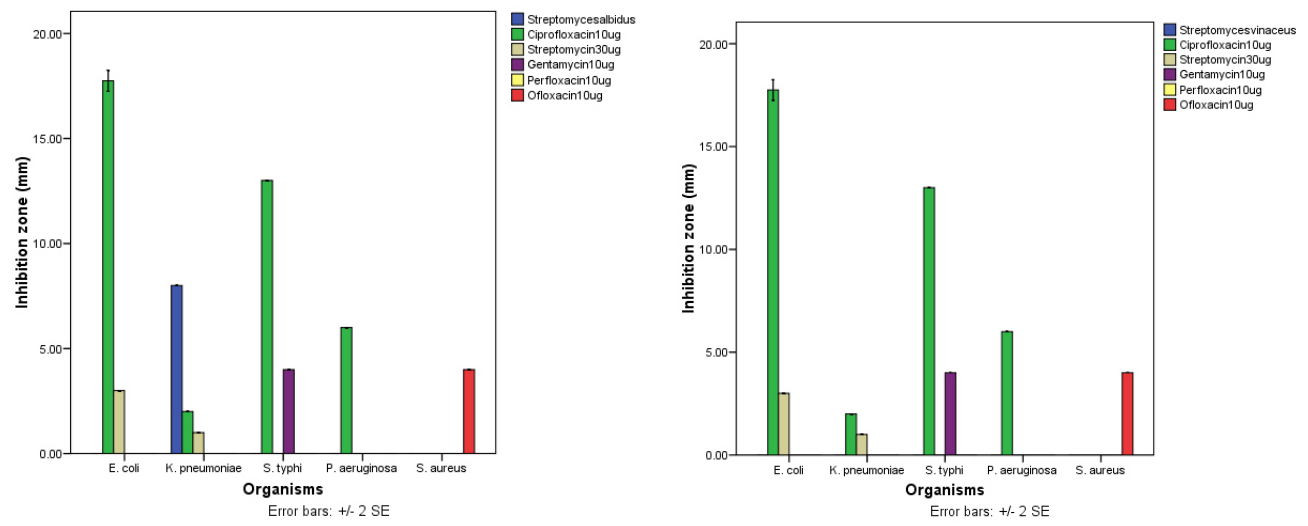

Fig. 3. Comparative antibacterial activities of Streptomyces albidus and commercial antibiotics on selected pathogenic organisms. Fig. 4. Comparative antibacterial activities of Streptomyces vinaceus and commercial antibiotics on selected pathogenic organisms. 

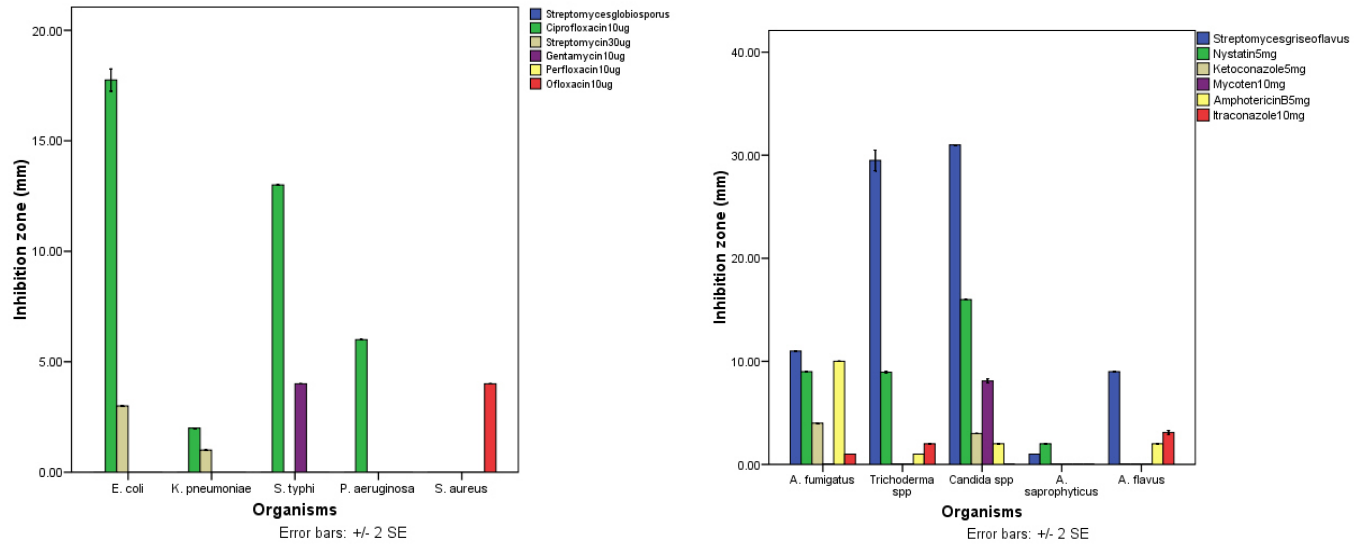

Fig. 5. Comparative antibacterial activities of Streptomyces globiosporus and commercial antibiotics on selected pathogenic organisms. Fig. 6. Comparative antifungal activities of Streptomyces griseoflavus and commercial antifungal drugs on selected pathogenic organisms.
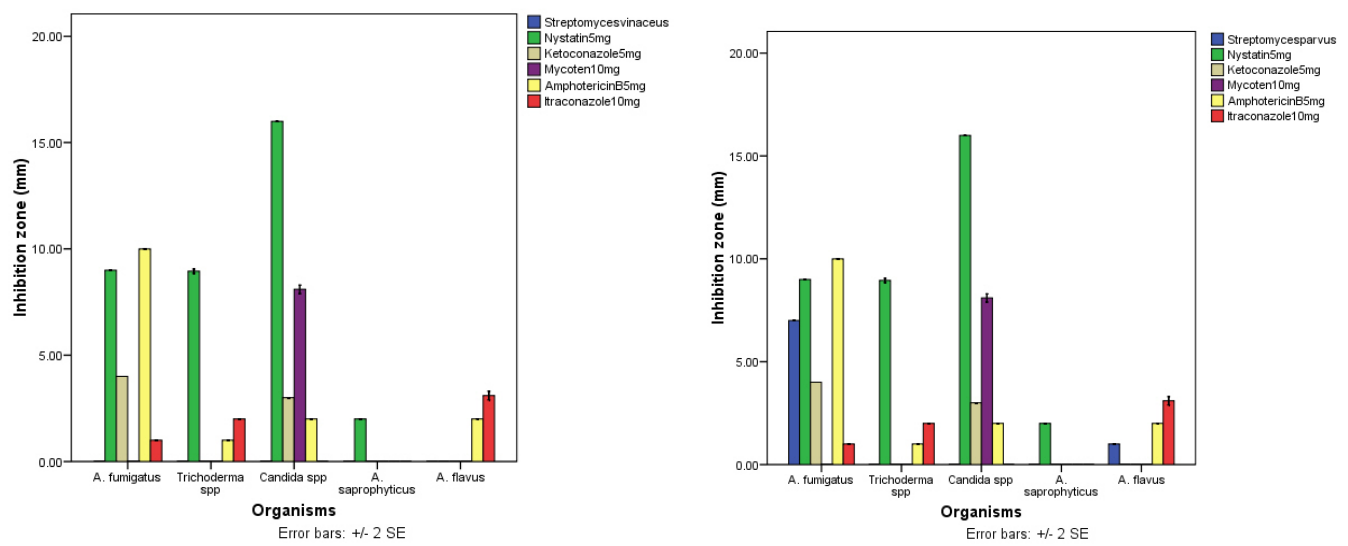

Fig. 7. Comparative antifungal activities of Streptomyces parvus and commercial antifungal drugs on selected pathogenic organisms. Fig. 8. Comparative antifungal activities of Streptomyces albidus and commercial antifungal drugs on selected pathogenic organisms. 

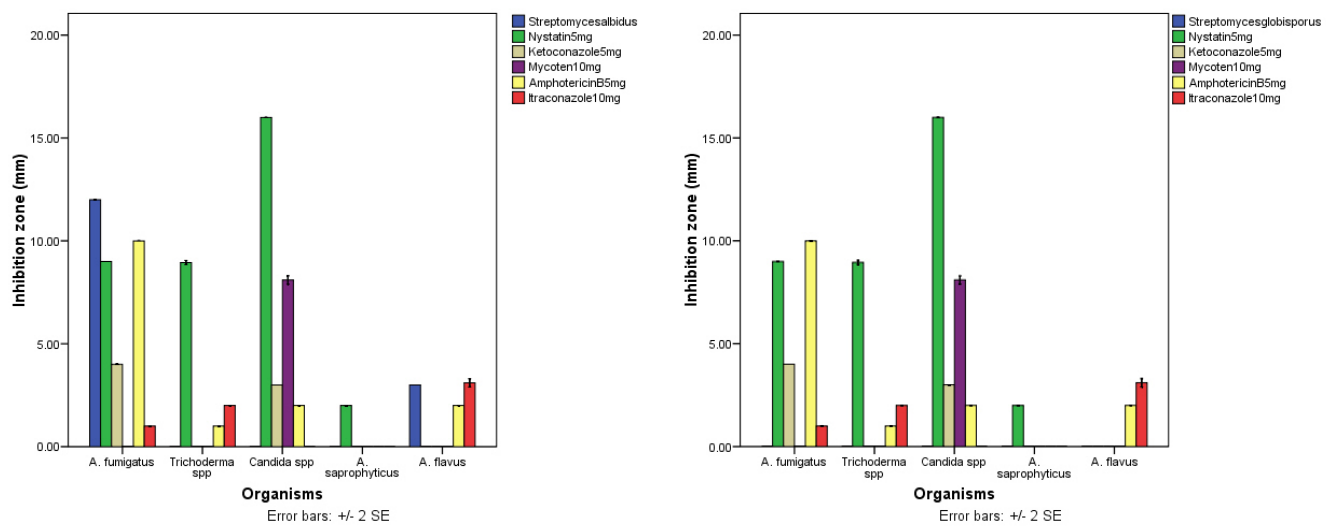

Fig. 9. Comparative antifungal activities of Streptomyces vinaceus and commercial antifungal drugs on selected pathogenic organisms. Fig. 10. Comparative antifungal activities of Streptomyces globiosporus and commercial antifungal drugs on selected pathogenic organisms.

The commercial antibiotics Ciprofloxacin showed inhibitory action against Escherichia coli with inhibition zone of $15 \mathrm{~mm}$. Also, Streptomyces parvus exhibited inhibitory action against Staphylococcus aureus but was not that effective against Escherichia coli when compared with ciprofloxacin (Figure 2). Streptomyces albidus seemed to be effective against Klebsiella pneumoniae with inhibition zone of $8 \mathrm{~mm}$ when compared with Ciprofloxacin and Streptomycin with zone inhibitions of $1.33 \mathrm{~mm}$ and $1.00 \mathrm{~mm}$ respectively. Streptomyces vinaceus and Streptomyces globiosporus did not show any antibacterial activities. Ciprofloxacin, a commercial antibiotic inhibited Escherichia coli, Salmonella typhi and Pseudomonas aeruginosa with inhibition zones $15.67 \mathrm{~mm}, 13.67 \mathrm{~mm}$ and $5.33 \mathrm{~mm}$ respectively (Figures 4 and 5).

It was determined that of the 5 isolates, $3(60 \%)$ produced distinct inhibitory substances against at least one indicator fungi. Among the active isolates, 3 inhibited the pathogenic fungi. The active isolates suppressed or inhibited fungal growth with inhibition zones ranging from 1 to $30 \mathrm{~mm}$. In general, activity of Streptomyces griseoflavus was specifically the highest on the pathogenic fungi than all the isolates and the standard antimicrobials used as positive controls (Figure 6 - 9). Streptomyces globiosporus did not have any antifungal effects (Figure 10).

\section{Discussion}

Findings from the present study have corroborated the submission of Demain and Davies (1999) with respect to the growth of Streptomyces isolates obtained. The colony forming units (c.f.u) were determined by counting the colonies on the dilution plates. Maximum number of colonies $\left(1.0 \times 10^{8} \mathrm{c}\right.$ c.f.u/gm of soil) was obtained from the dry soil sample that is chiefly used for maize cultivation. The physicochemical characteristics of the soil sample used indicate a considerable high level of calcium and phosphorus; $200400.00 \mathrm{Mg} / \mathrm{l}, 205977.10 \mathrm{Mg} / \mathrm{l}$ respectively. This we can say has contributed to the presence of the Streptomyces in the soil since these inorganic elements are vital components of the isolation media. Physicochemical attributes of the pond water sample showed a comparatively lower amount of calcium and phosphate; $17.000 \mathrm{mg} / \mathrm{l}, 1.400 \mathrm{mg} / \mathrm{l}$ respectively. These results agree with previous findings of Mustafa, (2009) that Streptomyces spp are prevalent in soil that is rich in exchangeable cations. This may likely be responsible for lesser number of Streptomyces isolated from the pond water sample. It can also be observed that there is greater number of Streptomyces in the dry soil than all other sources; this has been linked to the ability of Streptomyces to form spores and bridge soil spaces using mycelium, together with their ability to use a broad spectrum of suitable carbon sources and inorganic nitrogen, enable them to survive long term under extreme conditions (Ka"mpfer 2006). 
Screening the actinomycetes for antibacterial activities revealed that out of the 5 isolates, $3(60 \%)$ produced distinct inhibitory substances against at least one indicator bacterium. Three of the five Streptomyces isolates inhibit the test fungi by producing inhibition zones by a mechanism that involves the release of antifungal agents. This shows the antagonistic effect that these strains of Streptomyces and the evidence were summarized as follows; clear inhibition zones were seen after $48 \mathrm{hrs,} \mathrm{shows} \mathrm{wider} \mathrm{inhibition} \mathrm{zone} \mathrm{when}$ compared with the synthetic antifungal agents, spores do not germinate when cultured on the inhibition zone. Streptomyces griseoflavus and Streptomyces albidus inhibited Gram negative bacteria while Streptomyces parvus exhibited a broad spectrum antibacterial action against both Gram-negative and Gram-positive bacteria. The latter is at par with previous investigation that showed Streptomyces spp had activity against Gram-positive bacteria (Thakur et al. 2007). The active isolates generally inhibited bacteria growth with inhibition zones ranging from 0 to $39.33 \mathrm{~mm}$ and compete favorably with the standard, purified antibiotics. It should also be noted that the pathogenic organisms used were of hospital origin with track records of resistance to commercial antibiotics this was also shown as both the Gram-negative and Gram-positive bacteria were totally resistant to most of these antibiotics.

\section{Conclusion}

This study has provided information on the antibacterial activities of some Streptomyces spp isolated from fish pond water and garden soil of FUTA.

\section{Recommendation}

The garden soil of FUTA has Streptomyces with antibacterial activities; this could be an important source of bioactive metabolites that can either serve as substitute or enhancement for the commercial antibiotics. Further research is required to outline this potential. It is therefore suggested that broader clinical studies be done to measure this novel advantage, in order to convert it to improved clinically applicable outcomes.

\section{References}

Àarthi C M, Srinivasan K, Siva Kumar, Thangaradjou T. 2009. Screening of carbohydrate degrading enzyme producing thermophilic actinobacteria from the mud volcano sediments of Andaman. Natl Acad Sci Lett 32, 213-218.

Ahmed S A, Al-Domany R A, El-Shayeb N M A, Radwan H H, Saleh S A. 2008. Optimization, immobilization of extracellular alkaline protease and characterization of its enzymatic properties. Research Journal of Agriculture and Biological Sciences 4, 434-446.

Anderson A S, Wellington E M H. 2001. The taxonomy of Streptomyces and related genera. International Journal of Systematic and Evolutionary Microbiology 51, 797-814. http://dx.doi.org/10.1099/00207713-51-3-797

Association of Official Analytical Chemists. 2007. Official Methods of Analysis, 18th Edition, Published by Inc.; 2200 Wilson Boulevard; Arlington, Virginia 222013301, USA.

Berdy J. 2005. Bioactive microbial metabolites: A personal view. J Antibiotic 58(1), 1-26. http://dx.doi.org/10.1038/ja.2005.1

Chater K F, Biro S, Lee K J, Palmer T, Schremp F H. 2009. The complex extracellular biology of Streptomyces. FEMS Microbiol Rev 34, 171-198. http://dx.doi.org/10.1111/j.1574-6976.2009.00206.x

Demain A I, Davies J E. 1999. Manual of Industrial microbiology and Biotechnology, chapter 1, American Society for Microbiology, Washington, DC, USA, 2nd ed. 48, 3670-3676.

Demain A L. 2009. Antibiotics: Natural Products Essential to Human Health. Med Res Rev 29, 821-842. http://dx.doi.org/10.1002/med.20154

Fokkema N J. 1973. The role of saprophytic fungi in antagonism against Dreschlera sorokiniana (Helminthosporium sativum) on agar plates and rye leaves with pollen. Physiol Plant Path 3, 15-105. http://dx.doi.org/10.1016/00484059(73)90082-9

Ka"mpfer P. 2006. The family Streptomycetaceae, Part I: taxonomy. In: Dworkin M, Falkow S, Rosenberg E, Schleifer KH, Stackebrandt E. The prokaryotes, 3rd ed New York: Springer Science +Business Media, LLC; 538-604. 
Lee J Y, Lee J Y, Jung H W, Hwang B K. 2005. Streptomyces koyangensis sp. nov., a novel actinomycete that produces 4-phenyl-3-butenoic acid. Int J Syst Evol Microbiol 55, 257-262. http://dx.doi.org/10.1099/ijs.0.63168-0

Mellouli L, Ameur-Mehdi R B, Sioud S, Salem M, Bejar S. 2003. Isolation, purification and partial characterization of antibacterial activities produced by a newly isolated bioactive microbial metabolites. Microbiology 94, 127-137.

Mustafa 0 .2009. Comparison of Streptomyces diversity between agricultural and non-agricultural soils by using various culture media. Scientific Research and Essay 410, 997-1005.

Og L S, Choi G J, Choi Y H, Jang K S, Park D J, Kim C J, Kim J C. 2008. Isolation and Characterization of Endophytic Actinomycetes from Chinese Cabbage Roots as Antagonists to Plasmodiophora brassicae. J Microbiol Biotechnol $18,1741-1746$.

Okalebo J R, Gathua K W, Woomer P L. 2002. Laboratory Methods of Soil and Plant Analysis: A Working Manual, 2nd edition, Tropical soil Biology and Fertility and Soil Science society of East Africa pp. 128.

Panácek A, Kvítek L, Prucek R, Kolár M, Vecerová R, Pizúrová N, Sharma V K, Nevecná T, Zboril R. 2006. Silver colloid nanoparticles: synthesis, characterization, and their antibacterial activity. J Phys Chem B 110, 16248-16253. http://dx.doi.org/10.1021/jp063826h

Shirling E B, Gottlieb D.1966. Methods for characterization of Streptomyces species. International Journal of Systematic Bacteriology 16, 313-340. http://dx.doi.org/10.1099/00207713-16-3-313

Silva C, Fermino A C, Silva M. 2008. Characterization of Streptomycetes with potential to promote plant growth and biocontrol. Sci Agric (Piracicaba, Braz.) 65,50-55.

Sujatha P K, Raju B, Ramana T K V. 2005. Studies on a new marine streptomycete BT-408 producing polyketide antibiotic SBR-22 effective against methicillin resistant Staphylococcus aureus. Microbiol Res 160,119-126. http://dx.doi.org/10.1016/i.micres.2004.10.006

Suneetha V, Zaved A K. 2011. Screening, Characterization and Optimization of Microbial Pectinase, Soil Enzymology, Varma, A (eds) Springer-Verlag Berlin Heidelberg 329-337.

Thakur D, Yadav A, Gogoi B K, Bora TC. 2007. Isolation and screening of Streptomyces in soil of protected forest areas from the states of Assam and Tripura, India, for antimicrobial metabolites. Journal de Mycologie Médicale 17, 242249. http://dx.doi.org/10.1016/j.mycmed.2007.08.001

Watve M G, Tickoo R, Jog M M, Bhole B D. 2001. How many antibiotics are produced by the genus Streptomyces? Arch Microbiol 176,386-390. http://dx.doi.org/10.1007/s002030100345 